\title{
West syndrome treatment: new roads for an old syndrome
}

\author{
Piero Pavone ${ }^{1}$, Raffaele Falsaperla ${ }^{1}$, Martino Ruggieri ${ }^{2}$, Andrea Domenico Praticò ${ }^{1}$ and Lorenzo Pavone ${ }^{1 *}$
}

1 Unit of Pediatrics and Pediatrics Emergency, University Hospital "Vittorio Emanuele," Catania, Italy

2 Department of Educational Sciences, University of Catania, Catania, Italy

*Correspondence: Iorenzo_pavone@hotmail.com

Edited by:

Fernando Cendes, University of Campinas, Brazil

Reviewed by:

Peter Halasz, Hungarian Sleep Society, Hungary

\section{A commentary on}

West syndrome: response to valproate by Chandra, S., Bhave, A., Bhargava, R., Kumar, C., and Kumar, R. (2012). Front. Neurol.3:166. doi: 10.3389/fneur.2012.00166

The recent article by Chandra et al. (1), published in Frontiers in Neurology, on the treatment of West syndrome (WS) by using valproate as monotherapy, prompted us to rethink about the past and present treatment strategies and the outcome in this severe epileptic syndrome.

Even though the study by Chandra et al. (1) leaves some unsolved issues regarding the lack of demonstration of hypsarrhythmia in $70 \%$ of their cases, the long-term follow-up of cognitive profiles in the whole group, an extensive etiological work-up and the alternative use of new therapeutic drugs such as vigabatrin, it provides the scientific community with successful short-term results in 36/91 (40\%) of their treated WS patients who showed "... a greater than $80 \%$ decrease in the number of spasms or complete cessation."

Historically, some previous studies in children with WS, which employed valproate as monotherapy, proved effective in controlling either hypsarrhythmia and/ or the epileptic spasms (2-6). Besides valproate, zonisamide, topiramate, and nitrazepam (as monotherapy or in combination) showed good responses (ranging from 20 to $35 \%$ of treated patients) in WS (7-9). More effective, however, has proven the short-term treatment with hormonal therapy (i.e., by using the adrenocorticotropic hormone ACTH), which has been reported to succeed in $60-80 \%$ of the infants with WS treated (10). Therefore, nowadays the first-line treatment of WS and more in general of infantile spasms includes ACTH as well as vigabatrin (the latter being effective especially in infantile spasms in the setting of tuberous sclerosis) (11-13). Therefore, most recently the treatment of WS with valproate has been overtaken and overlooked $(14,15)$.

Overall, the treatment strategies in WS [either the first-line treatments (e.g., ACTH and vigabatrin) or the more classical nongolden treatments (e.g., valproate or other newer anticonvulsants)] are based on the assumption that an early initiation of therapy coupled with a rapid control of seizures in these patients may prevent the arrest or the decline in cognitive development.

However, the spectrum of disorders associated to clinical spasms with onset in infancy is wider than previously thought and is currently comprised under the umbrella term of Infantile Spasms syndrome (ISs), which defines an epileptic syndrome (occurring in children younger than 1 year - rarely older than 2 years), with clinical (epileptic: i.e., associated to an epileptiform EEG) spasms usually occurring in clusters whose most characteristic EEG finding is hypsarrhythmia (the spasms are often associated with developmental arrest or regression). WS refers to a form (a subset) of ISs, characterized by the combination of clustered spasms and hypsarrhythmia on an EEG. Additional (less common) phenotypes falling within the ISs include the so-called infantile spasms single-spasm variant (ISSV: in which spasms may occur singly rather than in clusters), hypsarrhythmia without infantile spasms [HWIS: in which hypsarrhythmia can be (incidentally) recorded without any evidence of clinical spasms], and infantile spasms without hypsarrhythmia (ISW: in which typical clinical spasms may manifest in absence of hypsarrhythmia) [reviewed in Lux and Osborne (11)]. There is a growing evidence that ISs and related phenotypes may result, besides from acquired events, from disturbances in key genetic pathways of brain development: specifically, in the gene regulatory network of GABAergic forebrain dorsal-ventral development, and abnormalities in molecules expressed at the synapse (16). Notably, children with these genetic associations also have phenotypes beyond epilepsy, including dysmorphic features, autism, movement disorders, and systemic malformations (16). In this respect, the ISs and related phenotypes, could be regarded as a (peculiar) type of neurological manifestation underlying the involvement of many different neuronal/interneuronal networks and, accordingly, the cognitive delay or arrest regarded as a (genetically predetermined) part of the (more or less severe) phenotype, which in turn is related to the type or severity of mutation or to the protein/molecule and/ or regulatory network involved.

For all the above reasons, the results of Chandra et al. (1) highlight the multifaceted aspects of the spectrum of disorders associated to clinical spasms (i.e., good response to a classical anticonvulsant in the era of newer drugs and other-than valproate first-line treatments) and the prevalent role that etiological events could play in pre-programing the cognitive and behavioral outcomes in the setting of ISs (16). In this respect, without forgetting the current first-line treatment strategies for ISs and related phenotypes, we should also look with less strict therapeutic boundaries at patients with clinical spasms as in the near future the gold standard could be the development of new therapies (with new or old molecules) that simply target specific pathways of pathogenesis, as currently occurs in tuberous sclerosis $(17,18)$.

\section{REFERENCES}

1. Chandra S, Bhave A, Bhargava R, Kumar C, Kumar R. West syndrome: response to valproate. Front Neurol (2012) 3:166. doi: 10.3389/fneur.2012.00166

2. Pavone L, Incorpora G, La Rosa M, Li Volti S, Mollica F. Treatment of infantile spasms with sodium 
dipropylacetic acid. Dev Med Child Neurol (1981) 23:454-61.doi: 10.1111/j.1469-8749.1981.tb02018.x

3. Dyken PR, Du Rant RH, Minden DB, King DW. Short term effects of valproate on infantile spasms. Pediatr Neurol (1985) 1:34-7. doi: 10.1016/0887-8994(85)90006-2

4. Seimes H, Spohr HL, Michael T, Nau H. Therapy of infantile spasms with valproate: results of a prospective study. Epilepsia (1988) 29:553-60. doi: 10.1111/j.1528-1157.1988.tb03760.x

5. Pratz JM, Garaizar C, Rua MJ, Garcia-Nieto ML, Madoz P. Infantile spasms treated with high doses of sodium valproate: initial response and follow-up. Dev Med Child Neurol (1991) 33:617-25. doi: 10.1111/j.1469-8749.1991.tb14932.x

6. OhtsukaY,Amano R,Mizukawa M,Oka E, Ohtahara S. Treatment of intractable childhood epilepsy with high dose valproate. Epilepsia (1992) 33:158-64.doi: 10.1111/j.1528-1157.1992.tb02300.x

7. Chamberlain MC. Nitrazepam for refractory infantile spasms and the Lennox-Gastaut syndrome. J Child Neurol (1996) 11:31-4. doi: 10.1177/088307389601100107

8. Suzuki Y. Zonisamide in West syndrome. Brain Dev (2001) 23:658-61. doi: 10.1016/ S0387-7604(01)00301-1

9. Hosain SA, Merchant S, Solomon GE, Chutorian A. Topiramate for the treatment of infantile spasms. J Child Neurol (2006) 21:17-9. doi: $10.1177 / 08830738060210011001$
10. Lux AL, Edwards SW, Hancock E, Johnson AL, KennedyCR,Newton RW, et al. The United Kingdom infantile spasms study comparing vigabatrin with prednisolone or tetracosactide at 14 days: a multicentre, randomised controlled trial. Lancet (2004) 364:1773-8. doi: 10.1016/S0140-6736(04)17400-X

11. Lux AL, Osborne JP. A proposal for case definitions and outcome measures in studies of infantile spasms and west syndrome: consensus statement of the west Delphi group. Epilepsia (2004) 45:1416-28. doi: 10.1111/j.0013-9580.2004.02404.x

12. Wheless JW, Clarke DF, Arzimanoglou A, Carpenter D. Treatment of pediatric epilepsy: European expert opinion. Epileptic Disord (2007) 9:353-412.

13. Brodie SE. Screening for vigabatrin (Sabril ${ }^{\circledR}$ ) retinal toxicity in children. Ophthalmic Genet (2011) 32:193-5. doi: 10.3109/13816810.2011.574185

14. MacKay M, Weiss S, Adams-Webberm T, Ashwal S, Stephens D, Ballaban-Gill K, et al. Practice parameter: medical treatment of infantile spasms. Report of the American academy of neurology and the child neurology society. Neurology (2004) 62:1668-81. doi: 10.1212/01.WNL.0000127773.72699.C8

15. Stafstrom CE, Arnason BG, Baram TZ, Catania A, Cortez MA, Glauser TA, et al. Treatment of infantile spasms: emerging insights from clinical and basic science perspectives. J Child Neurol (2011) 26:1411-21. doi: 10.1177/0883073811413129

16. Paciorkowski AR, Thio LL, Dobyns WB. Genetic and biologic classification of infantile spasms.
Pediatr Neurol (2011) 45:355-67. doi: 10.1016/j. pediatrneurol.2011.08.010

17. Curatolo P, Moavero R. mTOR inhibitors as a new therapeutic option for epilepsy. Expert Rev Neurother (2013) 13:627-38. doi: 10.1586/ ern.13.49

18. Krueger DA, Wilfong AA, Holland-Bouley K, Anderson AE, Agricola K, Tudor C, et al. Everolimus treatment of refractory epilepsy in tuberous sclerosis complex. Ann Neurol (2013). doi: 10.1002/ ana.23960 [Epub ahead of print]

Received: 25 June 2013; accepted: 27 July 2013; published online: 12 August 2013.

Citation: Pavone P, Falsaperla R, Ruggieri M, Praticò $A D$ and Pavone L (2013) West syndrome treatment: new roads for an old syndrome. Front. Neurol. 4:113. doi:10.3389/fneur.2013.00113

This article was submitted to Frontiers in Epilepsy, a specialty of Frontiers in Neurology.

Copyright $\odot 2013$ Pavone, Falsaperla, Ruggieri, Praticò and Pavone. This is an open-access article distributed under the terms of the Creative Commons Attribution License (CC BY). The use, distribution or reproduction in other forums is permitted, provided the original author(s) or licensor are credited and that the original publication in this journal is cited, in accordance with accepted academic practice. No use, distribution or reproduction is permitted which does not comply with these terms. 